\title{
TECNOLOGIA DIGITAL, ACESSIBILIDADE E NOVOS MERCADOS PARA O TRADUTOR AUDIOVISUAL
}

\author{
Sabrina Lopes Martinez
}

A tradução audiovisual, ou TAV, é marcada por evoluções tecnológicas constantes. Nos anos de 1980, as legendas para o mercado de home video eram feitas de forma improvisada. Em geral, os tradutores recebiam uma fita VHS, assistiam ao filme no aparelho de TV e usavam papel quadriculado ${ }^{1}$ para escrever as legendas, que depois eram digitadas em um gerador de caracteres diretamente na ilha de edição. Na década seguinte, com a chegada da televisão por assinatura no Brasil e a necessidade de se profissionalizar a tradução para legendagem, surge o primeiro software latinoamericano de preparação de legendas, o venezuelano Systimes. O programa rodava em MS-DOS e era bastante limitado em comparação aos programas disponíveis hoje, mas contava com vários recursos que agilizavam o trabalho do tradutor e melhoravam a qualidade geral das legendas, como contagem de toques por linha e limitação de número de caracteres por segundo. Além disso, no Systimes já era possível fazer a marcação do tempo de exibição das legendas e dos intervalos entre elas em segundos.

Nessa época, os tradutores precisavam investir em vários equipamentos para trabalhar com legendagem: além do material de apoio, como dicionários físicos e enciclopédias, os profissionais precisavam de um computador rodando o software Systimes, um televisor e um videocassete, este último operado através do controle remoto ou de um pedal adaptado ao aparelho. Esse pedal permitia que os comandos play, fast-forward e rewind fossem acionados com o pé, liberando as mãos do tradutor para a digitação. Nessa época, tais exigências tornavam o ofício bastante especializado, e poucos tradutores tinham a oportunidade de trabalhar com legendagem. Felizmente, de lá para cá, muita coisa mudou.

\footnotetext{
${ }^{1} \mathrm{O}$ papel quadriculado servia para que o tradutor não extrapolasse o número máximo de toques por linha, evitando assim que a legenda "vazasse" pelas laterais da tela de exibição.
} 
Em 1995, o advento do DVD (Digital Versatile Disc) fez aumentar o interesse pela tradução audiovisual, já que um único disco comporta até trinta e duas versões legendadas e oito versões dubladas do mesmo filme ou programa. A popularização dessa tecnologia criou um novo e rico mercado para os tradutores audiovisuais.

Por sua vez, os recém-criados canais de TV por assinatura precisavam preencher sua grade de programação, e a forma mais rápida, fácil e barata de fazê-lo era por meio da exibição de programas estrangeiros. Para traduzi-los, a modalidade de TAV adotada por praticamente todos os canais no Brasil foi a legendagem ${ }^{2}$. Existem dois motivos principais para essa escolha: em primeiro lugar, as legendas são uma opção barata e rápida de tradução de produtos audiovisuais. A título de comparação, a produção da dublagem de um programa custa de dez a quinze vezes mais do que a legendagem do mesmo programa. Em segundo lugar, como a assinatura naquele primeiro momento era muito cara, e portanto só acessível à elite, as distribuidoras julgaram que a manutenção do áudio original serviria como um atrativo adicional para os assinantes, aposta que se confirmou.

No início dos anos 2000, outra revolução. O processo de gravação de uma VHS a partir da fita original foi substituído pela digitalização dos arquivos de vídeo, a qual tornou dispensável o uso do videocassete e do aparelho de TV pelo tradutor. Com os arquivos digitalizados, a única ferramenta necessária para a elaboração de legendas passou a ser o computador, equipado com um dos softwares próprios, que nessa época se multiplicavam no mercado em versões de baixo custo ou até mesmo gratuitas. A essa altura, grande parte do material de apoio usado pelos tradutores, como dicionários, enciclopédias e livros de referência, já contava com versões digitais, o que facilitou e agilizou a pesquisa para a tradução. As chamadas fansubs, ou legendas traduzidas por fãs, tinham deixado de ser produzidas apenas para os animes japoneses e se disseminavam pela Internet, dada a facilidade do tráfego de arquivos de vídeo e de legendas pela rede. A disseminação entre os próprios fãs, principalmente jovens, do impulso de produzir e distribuir legendas para seus produtos audiovisuais favoritos filmes, séries e desenhos animados - levou tanto à popularização da prática da legendagem quanto ao desenvolvimento de novos softwares para criação, marcação e exibição de legendas. Mais recentemente, a dublagem, uma modalidade mais especializada do que a legendagem por envolver atores e diretores de dublagem,

\footnotetext{
${ }^{2} \mathrm{O}$ voice-over, uma forma mais barata de dublagem, foi adotado por canais que exibem principalmente documentários em sua programação.
} 
também vem ganhando uma certa popularidade através das fandubs. A ideia é a mesma das fansubs: fãs produzem de forma amadora dublagens para seus animes e games preferidos.

Menos de uma década depois do surgimento do DVD, a implantação da TV digital abriu novos caminhos para os tradutores audiovisuais, uma vez que, de forma similar ao que ocorreu com o advento do DVD, a tecnologia digital possibilita a transmissão simultânea de diversas versões legendadas e dubladas da mesma programação. Pode-se dizer que a televisão digital está para a analógica, assim como o DVD está para o CD. Um DVD armazena entre 4,7 e 17GB, enquanto um CD tem a capacidade média de $700 \mathrm{MB}^{3}$. Em contraste com a TV analógica, a digital possibilita a difusão simultânea de áudio, vídeo e sinais de dados, proporcionando assim a transmissão de maior quantidade de conteúdo em melhor qualidade. E a transmissão digital mudou a relação do telespectador com a televisão, pois permite, entre outros inúmeros recursos, que o cliente grave seus programas preferidos para assistir a qualquer hora, e que um programa seja exibido ao mesmo tempo em diferentes versões dubladas e legendadas.

Essa inovação representa um novo mercado para o tradutor audiovisual. As leis que regulamentam a acessibilidade no campo da comunicação televisiva, através da legenda oculta e da audiodescrição, estão levando os canais da TV aberta a disponibilizar esses recursos em sua programação, e a demanda por profissionais especializados nessas modalidades de tradução audiovisual é cada vez maior.

Cabe aqui um esclarecimento terminológico: a nomenclatura "legenda oculta" é usada pelo governo brasileiro nos textos das legislações que tratam do assunto. A expressão mais comumente adotada pela academia é "legenda fechada", terminologia que se tornou obsoleta por ter deixado de designar exclusivamente as legendas produzidas para surdos e ensurdecidos, já que se entendia por legenda fechada aquela que era ativada através de um botão no controle remoto. Hoje, com a legendagem eletrônica, as legendas tradicionais, ou seja, interlinguais, também podem ser ativadas e desativadas através do controle remoto, uma vez que não são mais "queimadas", ou gravadas, na mídia final. Já o termo "closed caption", utilizado pela indústria audiovisual, refere-se ao padrão americano de legendagem oculta adotado no Brasil

\footnotetext{
${ }^{3}$ Em mais um exemplo de evolução tecnológica, o Blu-ray, substituto do DVD, já está ganhando espaço no mercado. Esse formato tem capacidade de armazenamento de até $50 \mathrm{~GB}$, permitindo a gravação de filmes e jogos em alta definição.
} 
(Selvatici, 2010, p. 30), e é um recurso bem conhecido dos telespectadores brasileiros, pois está disponível na nossa programação desde 1997. O decreto $\mathrm{n}^{\circ} 5.296$, de 2 de dezembro de 2004, regulamentou as leis $\mathrm{n}^{\mathrm{o}} 10.048$ e 10.098 , que tratam da acessibilidade das pessoas portadoras de deficiência ou com mobilidade reduzida, e a portaria 310, de 27 de junho de 2006, definiu os prazos de implantação do recurso de legenda oculta. A lei entrou em vigor em 2008, e hoje a inserção do closed caption é obrigatória em pelo menos oito horas diárias da programação televisiva. Até 2019, $100 \%$ da programação das emissoras brasileiras deverão contar com o recurso. Existem duas modalidades de closed caption: quando é feita para acompanhar programas transmitidos ao vivo, como telejornais ou transmissões esportivas, é conhecida como online, e offline quando pós-produzida para acompanhar, por exemplo, um filme ou episódio de seriado.

Desde o dia $1^{\circ}$ de julho de 2011, as emissoras de TV aberta do Brasil com sinal digital estão obrigadas ainda a exibir no mínimo duas horas de programação semanal acompanhadas de audiodescrição. A portaria nº 188 do Ministério das Comunicações, datada de 24 de março de 2010, trata do calendário de implantação da audiodescrição no Brasil e determina que as emissoras acrescentem, a cada dois anos, duas horas semanais de programação audiodescrita em sua grade, até chegarem a um mínimo de vinte horas semanais em dez anos ${ }^{4}$. Ainda é pouco, pois vinte horas por semana equivalem a menos de três horas por dia de programas acessíveis a cegos e deficientes visuais. Por outro lado, deve-se comemorar que a lei de acessibilidade já esteja em vigor, levando as emissoras de TV aberta à adoção de iniciativas que lhes permitam adaptar-se a esses novos formatos.

Além disso, embora os canais de TV digital — aberta ou por assinatura — ainda não ofereçam todos esses recursos, a tecnologia de transmissão digital permite que, por meio do controle remoto, o telespectador escolha assistir a um programa: 1) com o áudio original, sem legendas em português; 2) com o áudio original, com legendas em português; 3) com o áudio original, com legendas originais (closed captions, quando disponível); 4) com o áudio dublado em português, sem legendas em português; 5) com o áudio dublado em português, com legendas em português; 6) com o áudio em português (seja original ou dublado), com closed captions; 7) com o áudio original ou

\footnotetext{
${ }^{4}$ Fonte: Associação Brasileira de Emissoras de Rádio e Televisão, ABERT.
} 
MARTINEZ - Tecnologia digital, acessibilidade e novos mercados...

dublado, com audiodescrição, entre outras combinações com janela de LIBRAS (Linguagem Brasileira de Sinais).

Tecnicamente, para que o telespectador tenha a opção de ativar ou desativar as legendas, elas não podem mais ser "queimadas" nas respectivas mídias ou suportes físicos (fitas ou discos), constituindo o que se conhece como "legendagem eletrônica". Esse recurso, que consiste em transmitir em paralelo as legendas que o espectador escolhe receber ou não, por um lado resulta em perda de renda para as empresas de legendagem, na medida em que dispensa a etapa da gravação das legendas na ilha de edição, mas por outro lado pode simplificar e agilizar seu processo de trabalho, já que ficam desobrigadas da remessa de seu produto finalizado em forma de mídia física, podendo mesmo enviar o arquivo de legendas por e-mail para a emissora ou distribuidora contratante. A contrapartida, de que hoje ouvimos ecos polêmicos na imprensa especializada, é a perda de precisão na sincronia e outros problemas técnicos associados à emissão separada de legendas e programação.

Já a dublagem, modalidade que até recentemente tinha pouca presença na TV fechada no Brasil - salvo em canais infantis ou exclusivamente dedicados à programação dublada -, vem ganhando espaço rapidamente, num esforço das programadoras de popularizar a TV por assinatura no país. Uma vez que a tecnologia possibilita a exibição de produtos audiovisuais com várias opções de tradução, um único programa pode gerar trabalho para pelo menos quatro profissionais: o tradutor responsável pelas legendas interlinguais, o responsável pela adaptação do roteiro para dublagem, o audiodescritor e o criador de legendas intralinguais para closed caption offline, além dos revisores envolvidos nos quatro processos.

No entanto, ocorre nos dias de hoje uma controvérsia envolvendo alguns canais de TV a cabo, que começam a exibir séries e longas-metragens apenas na opção dublada, e os assinantes mais antigos, que têm se revoltado e organizado boicotes. A justificativa dos canais de TV é que essa é uma "tendência do mercado", e que "[a] demanda [por dublagem] se deve ao aumento do número de assinantes", como noticiou a jornalista Lívia Brandão em matéria para a Revista da TV, do jornal $O$ Globo, em 28 de agosto. Ainda segundo a jornalista, "[m]uitos dos novos usuários se habituaram à dublagem nos canais abertos e preferem receber o conteúdo em português" (Brandão, 2011). Sabemos que esses são os usuários das classes C e D, que, graças ao aumento do poder aquisitivo dessas faixas da população, agora têm acesso ao serviço de assinatura de TV a cabo. 
MARTINEZ - Tecnologia digital, acessibilidade e novos mercados...

Particularmente, não vejo muito sentido nem argumentos sólidos que justifiquem essa decisão, que vai de encontro à tendência cada vez maior, inclusive em termos de legislação, à acessibilidade de todos os cidadãos aos produtos audiovisuais. Uma vez que a tecnologia digital permite, como já dissemos, a difusão simultânea de canais com o áudio original, o áudio dublado e a audiodescrição, além de inúmeros canais de dados que podem armazenar as legendas e o closed caption, por que não oferecer esses recursos aos assinantes? Vale lembrar que, muitas vezes, as legendas das séries que estão sendo exibidas somente dubladas já estão prontas, pois várias delas estão sendo reapresentadas e foram exibidas originalmente só na versão legendada. $\mathrm{Na}$ mesma matéria destacada acima, o gerente geral da Sony Pictures Television no Brasil, Alberto Niccoli Junior, diz que a opção pela dublagem se deve a uma limitação técnica: "Estamos caminhando aos poucos para exibir todas as nossas séries dubladas porque só poderemos dar a opção de legendar o áudio original em abril de 2012”. Niccoli alega que uma pesquisa de opinião "apontou empate entre os que preferem a programação dublada e os que gostam mais do áudio original", e que esse resultado teria levado os canais Sony a decidir veicular seu conteúdo apenas na versão dublada. Entretanto, embora nem ele nem sua entrevistadora esclareçam quais são as limitações técnicas que impediriam a exibição do áudio original com legendas antes de 2012, no fïm das contas parece ser de fato algum tipo de limitação, seja técnica ou de custos, que faz mais sentido para explicar essa falta de opção, e não uma escolha de caráter mercadológico. Afinal, se é possível agradar a todos dos assinantes oferecendo as duas opções de tradução, por que só agradar à metade deles?

Yves Gambier resume bem a importância da inclusão social e da acessibilidade nas discussões e pesquisas sobre tradução audiovisual nos dias de hoje:

A distribuição de produtos audiovisuais também está envolvida nessa tendência [à acessibilidade], uma vez que é importante atender às necessidades de segmentos de usuários tais como os surdos. A questão da acessibilidade, porém, não tem a ver apenas com necessidades especiais, sejam elas visuais, auditivas, motoras ou cognitivas; tal visão do problema é restritiva demais, tendo em vista a exclusão digital, as variações do uso da Internet ligadas às diferenças de renda e a falta de acesso à informação de certos setores da sociedade. A acessibilidade implica que os produtos e serviços audiovisuais ou eletrônicos sejam postos à disposição de todos os usuários, independentemente de questões como o lugar onde vivem, seu nível de experiência, sua capacidade física e mental ou configuração de seus computadores. A acessibilidade não visa apenas os deficientes: não significa somente uma situação livre de barreiras; significa também que os serviços estejam disponíveis e que as informações sejam amplamente distribuídas e fáceis de entender. (2006, p. 4, tradução própria) 
MARTINEZ - Tecnologia digital, acessibilidade e novos mercados...

Como eu disse, a controvérsia que a recente onda de dublagem de séries e longas-metragens criou está movimentando a imprensa. Desde a publicação da matéria de Lívia Brandão em 28 de agosto, só no jornal $O$ Globo apareceram mais dois textos sobre o assunto. Uma reportagem de capa da Revista da TV, no dia 20 de novembro, intitulada "Na ponta da língua: substituição da legendagem pela dublagem na TV fechada cria polêmica entre o público e ainda movimenta o mercado" (Contreras \& Britto, 2011), e uma crítica - "A nova TV a cabo" - da jornalista Patrícia Kogut em sua coluna, publicada no dia 7 de dezembro. No texto, além de constatar a disseminação da dublagem na televisão por assinatura graças ao crescente poder aquisitivo da classe C, Kogut lembra que "os filmes legendados, além de responsáveis por muitas das assinaturas, são praticamente a representação simbólica da diferença entre a TV aberta e a fechada”. E a jornalista finaliza explicando que as legendas continuam disponíveis em vários canais por assinatura através de uma tecla do controle remoto. O problema é, por um lado, a falta de informação por parte do telespectador, muitas vezes por não the ter sido mesmo transmitida, e, por outro, o desconhecimento da tecnologia por parte dos próprios técnicos de algumas operadoras de TV a cabo ou via satélite.

Portanto, a discussão aparentemente eterna entre os defensores da legendagem e os partidários da dublagem parece mesmo com os dias contados. A palavra de ordem na indústria audiovisual hoje é "inclusão", uma vez que os espectadores estão muito mais exigentes e contam com inúmeros canais de informação e muito mais meios de chamar atenção para suas insatisfações. Graças à evolução tecnológica, a forma como acessamos e consumimos obras audiovisuais está mudando rapidamente. A pirataria na Internet, com o "tráfico" amplamente disseminado de episódios de seriados e filmes, assim como as legendas e dublagens produzidas e distribuídas por fãs, obrigou as programadoras a reduzir o intervalo entre a exibição dos programas no país de origem e no Brasil, o que por sua vez afeta a vida do tradutor audiovisual, que precisa trabalhar ainda mais depressa.

Além disso, e para concluir, há que se considerar que, hoje, a programação chega ao consumidor não só pela televisão, mas também via Internet, através de aparelhos como computadores, tablets e telefones celulares. A tecnologia digital barateou e agilizou a gravação, edição, cópia, distribuição e o lançamento do material audiovisual (Gambier, 2006, p. 1). Os novos formatos e durações dos programas darão um impulso renovado à dublagem e à legendagem, e mais uma vez obrigarão os profissionais a se ajustarem às novas linguagens e tecnologias. Se a TAV já é o tipo de 
tradução mais consumido na atualidade, com a popularização da TV digital sua relevância aumentará ainda mais.

\section{Referências bibliográficas}

ABERT. Associação Brasileira de Emissoras de Rádio e Televisão. Recursos de Acessibilidade. Manual eletrônico sem numeração de páginas. Disponível em: <http://www.abert.org.br/site/images/stories/pdf/resultado/Manual_Recursos_Ac essibilidade_TV_v.2.pdf $>$. Acesso em: 12 dez. 2011.

BRANDÃO, Lívia. Depois de protestos dos telespectadores, canais como FX e Sony Spin explicam o motivo da troca das legendas por dublagem nas séries de TV. $\mathbf{O}$ Globo, Rio de Janeiro, 28 ago. 2011. Revista da TV. Disponível em: http://oglobo.globo.com/cultura/revistadatv/mat/2011/08/26/depois-de-protestosdos-telespectadores-canais-como-fx-sony-spin-explicam-motivo-da-troca-daslegendas-por-dublagem-nas-series-de-tv-925224984.asp. Acesso em: 15 out. 2011.

CONTRERAS, Tatiana; BRITTO, Thaís. Na ponta da língua: substituição da legendagem pela dublagem na TV fechada cria polêmica entre o público e ainda movimenta o mercado. O Globo, Rio de Janeiro, 20 nov. 2011. Revisa da TV.

DÍAZ-CINTAS, Jorge; SÁNCHEZ, Pablo Muñoz. Fansubs: audiovisual translation in an amateur environment. Journal of Specialised Translation, n. 6, p. 37-52, July 2006. Disponível em: http://www.jostrans.org/issue06/art_diaz_munoz.pdf. Acesso em: 10 out. 2011.

GAMBIER, Yves. Multimodality and Audiovisual Translation, 2006. Disponível em: http://www.euroconferences.info/proceedings/2006_Proceedings/2006_Gambier _Yves.pdf. Acesso em: 10 out. 2011.

KOGUT, Patrícia. Crítica: a nova TV a cabo. O Globo, Rio de Janeiro, 7 dez. 2011. Revista da TV. Disponível em 〈http://oglobo.globo.com/cultura/kogut/?palavra=A+nova+TV+a+cabo $>$. Acesso em: 8 dez. 2011.

SELVATICI, Carolina. Closed caption: conquistas e questões. Rio de Janeiro, 2010. Dissertação (Mestrado em Estudos da Linguagem) - Programa de PósGraduação em Letras, PUC-Rio. 